\title{
Characteristics of airborne Pm2.5 and Pm2.5-10 in the urban environment of Kuala Lumpur
}

\begin{abstract}
Gravimetric and elemental analyses were conducted at a site in Kuala Lumpur from 2008 to 2010, representing the local air quality of urban and traffic. Eighteen elements were detected by ED-XRF and was further analysed for enrichment factor and correlation study. About $19.7 \%$ elements were identified and detected in PM10, including 8.2\% and $11.5 \%$ in fine and coarse fractions, respectively. Al was found predominant in coarse fraction. However its composition in PM2.5 was highly enriched pointed to some anthropogenic emission source. In fine particulates, the total mass was mostly dominated by $\mathrm{Al}, \mathrm{K}, \mathrm{Mg}$ and $\mathrm{S}$. Those elements, probably from biomass burning accounted for more than $90 \%$ of total elemental detected in PM2.5.
\end{abstract}

Keyword: ED-XRF; PM2.5; PM2.5-10; Enrichment factor 